\title{
Using Fly Ash and Rice Husk Ash as Soil Improving Materials along with its Cost Effectiveness in Flexible Pavement Construction
}

\author{
Afaq Ali ${ }^{1}$, Prof. Dr. Sher Afzal Khan ${ }^{2}$, Engr Fazle Karim ${ }^{3}$ \\ 12 Sarhad University of Science \& Information Technology, Peshawar \\ afaqali369@gmail.com ${ }^{1}$,hod.civil@suit.edu.pk ${ }^{2}$,engr_fazli@yahoo.com ${ }^{3}$ \\ Received: 15 November, Revised: 25 November, Accepted: 26 November
}

\begin{abstract}
Unstable soil has always been a hurdle in swift construction projects, which can only be eradicated by soil stabilization. Soil stabilization is used for a plethora of projects; however, it is more common in pavement construction, where the purpose is to enhance the strength of soil and to minimize the expenses by providing indigenous available materials. Thus the use of alternative materials like coal combustion product (fly ash) and agriculture waste (Rice husk ash) will certainly lower the cost of construction and therefore reducing the environmental hazards. Hydrometer analysis, Atterberg limits, modified proctor test and California Bearing Ratio (CBR) tests were carried out on the natural soil. Next three different percentages of fly ash $(5 \%, 10 \%$ and $15 \%)$ were mixed with soil for the CBR test. In this study, the Rice Husk Ash (RHA) was also used for soil stabilization same as the percentages $(5 \%, 10 \%$ and $15 \%$ ) we selected in stabilization for fly ash. After finding CBR, the pavement was designed for natural soil and stabilized soil. The detail cost estimation was performed for $1 \mathrm{~km}$ long and $7.62 \mathrm{~m}$ wide road construction with specific thicknesses of designing road on natural soil and stabilized soil. In conclusion, the fly ash and RHA resulted in less thickness of road layers as compared to road design on natural soil. Furthermore, it was also concluded that the road construction cost using the fly ash and RHA is significantly less than the natural soil.
\end{abstract}

Keywords - Stabilization, Fly ash, Rice Husk Ash, Hydrometer analysis, California Bearing Ratio.

\section{INTRODUCTION}

Civil engineering infrastructure projects located in areas with soft or clay soils need to be improved for the construction purposes. Different methods are used to improve the soil properties, i.e. chemical, mechanical or by adding modifiers to soil such as fly ash, cement, lime, RHA etc. The chemical and mechanical process of stabilization is quite expensive; therefore, economical stabilizers are used for soil stabilization. For different engineering works, soil stabilization is being used, but it is mostly carried out in the pavement construction. The purpose of stabilization is to enhance the strength of soil and to minimize the expenses by providing locally available materials. Usually cement and lime were being used for stabilization, but these materials expenses have surged with the passage of time. Thus the use of coal combustion product (fly ash) and agriculture waste (RHA) will certainly lower the cost of construction as well as reducing the environmental hazards they causes. Fly ash is a fine particle obtained from the combustion of pulverized coal and RHA is obtained from the milling of rice. In retrospect, when fly ash and RHA were not introduced to construction projects, they were simply disposed off, which is not environment friendly and cause many diseases. With the application of these kinds of waste materials, there will be no need of materials to buy like cement, lime (which is expensive) and will help the environment clean. Fly ash is a pozzolanic material; pozzolan has siliceous and aluminous properties [14].

This study shows the optimum amount of fly ash and rice husk ash for subgrade purposes through the effect of fly ash and RHA on subgrade California bearing ratio, optimum moisture content (OMC) and maximum dry density (MDD) test were carried out. Road design is carried out on natural soil, soil with fly ash mix (at $10 \%$ fly ash) and soil with RHA mix (at $10 \%$ RHA). After designing, the detail cost estimation is done for natural soil, soil with fly ash and soil with RHA.

A study was done in the improvement of the expansive soil by adding a different percentage of fly ash with soil. The MDD and workability is observed at $25 \%$ fly ash with soil [3]. A class F fly ash was used to improve the expansive soil of south Texas. The soil sample is prepared with $20 \%$ fly ash in it and for comparison, the $6 \%$ lime and $10 \%$ Portland cement was also selected. From results, these three materials improve the soil properties like plasticity and unified compressive strength of soil [7]. A Study was carried out on the effect of self-cementing (class C) fly ash on soil stabilization for a wide range of construction applications. Moisture control, compaction and rate of ash hydration affect the procedure of soil stabilization [8]. Fly ash was used to stabilize the organic soil and then the strength tests were performed on it. Untreated soil specimen and fly ash with organic soil, the unconfined compressive strength (UCS) and resilient modulus test were performed. The UCS and resilient modulus of the organic soil improves by adding fly ash, but it depends on the soil and fly ash properties [12]. A study was carried out on the stabilization of soft grained soil with selfcementing fly ash. At different percentage, specimens were prepared, resilient modulus, CBR and UCS test were performed on the sample. At $18 \%$ of fly ash, the best improvement in the CBR was noticed [1]. An investigation was carried out on geotechnical properties of expansive soil by using fly ash and 
lime. From the results, fly ash and lime increases the MDD, free swell decreases and OMC and CBR increases [6]. Similarly, freeze-thaw durability, enhance with the use of fly ash in soil improvement [10].

The laboratory tests like CBR and UCS were performed by using RHA as a soil stabilizer. By adding RHA content to soil, the OMC increases and MDD decreases and CBR and UCS improved [2]. A study carried about the improvement of different types of soil by using RHA. The results show that liquid limits was decreased by $(11-18 \%)$ at $9 \%$ RHA and plasticity index decreased by (32-80\%). RHA shows a general increase in the OMC and decrease in MDD at 9\%. At (6-8\%), addition of RHA content, the UCS was also increased [5]. An investigation of the effect of RHA on soil engineering properties for stabilization was studied. By addition of RHA to clayey soil, the soaked CBR improves from $2.4 \%$ to $4.4 \%$ [11]. The laboratory tests like Atterberg limits, CBR and UCS were carried out by using fly ash and RHA in black cotton soil. At $12 \%$ fly ash and 9\% RHA content, the maximum improvements were noticed in CBR and UCS [13]. A wetting and drying phenomena of expansive soil cause a lot of problems in swift construction projects of civil engineering like highways. Fly ash in an industrial waste, results better in term of expenses and also utilization of fly ash in such projects can reduce many environmental hazards they cause. In this study fly ash and limefly ash mix was used in expansive soil to study its effectiveness and potential [15]. A study was evaluated on the soil of Indiana to check the engineering properties of soil with utilization of class $\mathrm{C}$ fly ash and loess (loess-fly ash mix). It was concluded that the optimum fly ash content used in a loess soil in wet condition avoid delay in the construction of road [16]. An experimental study was conducted on the stabilization of expansive soil by using the fly ash and cement to enhance the geotechnical properties of soil. For this study, various percentages of fly ash $(0,5,10,15$ and $20 \%)$ with $5 \%$ cement were taken to evaluate its effectiveness on soil stabilization. It was also concluded that, cement-fly ash mix was recommended to use in the subgrades where clayey, soft grained and expansive soil were found [17]

The objectives of the study are:

- Using RHA and fly ash for stabilization purposes

- To design the pavement thickness before and after using the soil stabilizers

- To assess the use of fly ash and RHA cost effectiveness as soil stabilizers.

\section{METHODOLOGY}

The soil sample for this study was collected from local area at Pabbi near the GT road, Nowshera Khyber Pakhtunkhwa, Pakistan. The laboratory test (hydrometer analysis and atterberg limits) shows that the collected soil is clay soil (A6) with low plasticity (CL).

The fly ash was collected from Tradeworth international fly ash, upper Gizri, Karachi. The fly ash used for this study is class $\mathrm{C}$ fly ash, which has $\mathrm{SiO} 2+\mathrm{Al} 2 \mathrm{O} 3+\mathrm{F} 2 \mathrm{O} 3$ greater than $50 \%$. Fly ash is a pozzolanic material having siliceous and aluminous properties [4].
RHA was collected from local area Bannu rice mill and passed through sieve number 200 before use. RHA is highly pozzolanic material depends on the firing temperature and retention period. $60 \%$ to $90 \%$ silica is present in the RHA, which is highly reactive [9]

\section{A. Conventional tests}

The laboratory tests carried out on natural soil, including wet sieving, atterberg limits, modified proctor test and CBR. The term OMC is used for preparing the samples for CBR test.

\section{B. CBR tests}

Three various percentages of fly ash (5\%,10\% and 15\%) are mixed with soil for the CBR test. In CBR, three samples on 5\% fly ash with virgin soil are prepared on three different blows (10, 30, and 65) and these samples were placed into water for 96hours. After 96hours, the samples were subjected to CBR machine. The same method was used for remaining $10 \%$ and $15 \%$ fly ash mixes with natural soil. After fly ash, the RHA was used for soil improvement same as the percentages (5\%,10\% and $15 \%$ ) we opted in stabilization in fly ash.

\section{Road design and Cost estimation}

After soil stabilization, the traffic volume survey was conducted on the GT road Nowshera N5 to find out the equivalent single axle load (ESAL) for road designing. The pavement was designed using the natural soil as subgrade against ESAL. In comparison, the pavement was also designed for treated soil for both fly ash and RHA. The pavement was designed for $1 \mathrm{~km}$ long and $7.62 \mathrm{~m}$ wide.

Similarly, detail cost estimation was done for $1 \mathrm{~km}$ long and $7.62 \mathrm{~m}$ wide road construction with specific thicknesses of designing road on natural soil and treated soil.

\section{RESULTS AND DISCUSSION}

\section{A. Hydrometer analysis/Wet sieving}

The soil is passed through sieve no 200 by water, to separate the sand particles from the soil. The sand particles which retained on sieve 200, passed through sieve analysis and on the soil hydrometer analysis test were performed. In the grain size distribution curve the blue line indicates the sieve analysis (sand particles) and the red line is a hydrometer analysis (silt and clay) shown in fig 1. 


\section{GRAIN SIZE DISTRIBUTION CURVE}

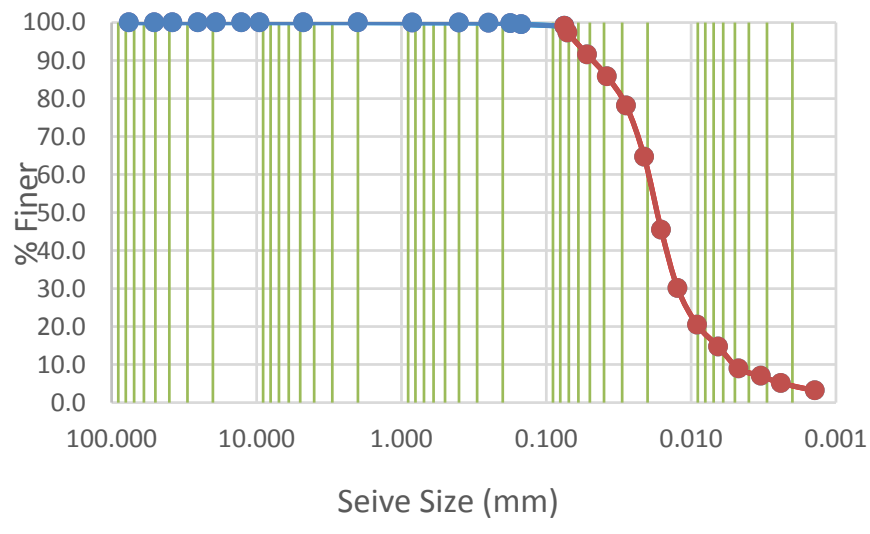

Fig 1: A grain size distribution curve of soil

\section{B. Atterberg limits}

To find out the plasticity index of the soil, Atterberg limits test was performed. In fig 2, the blue dot indicates that the soil is low plastic clay (CL).

\begin{tabular}{|c|c|c|}
\hline \multicolumn{3}{|c|}{ TABLE 1: Atterberg Limits } \\
\hline \multicolumn{3}{|c|}{ Atterberg limits } \\
\hline Liquid limit \% & $\begin{array}{c}\text { Plastic } \\
\text { limit \% }\end{array}$ & $\begin{array}{c}\text { Plasticity } \\
\text { index \% }\end{array}$ \\
\hline 34.1 & 14 & 20.1 \\
\hline
\end{tabular}

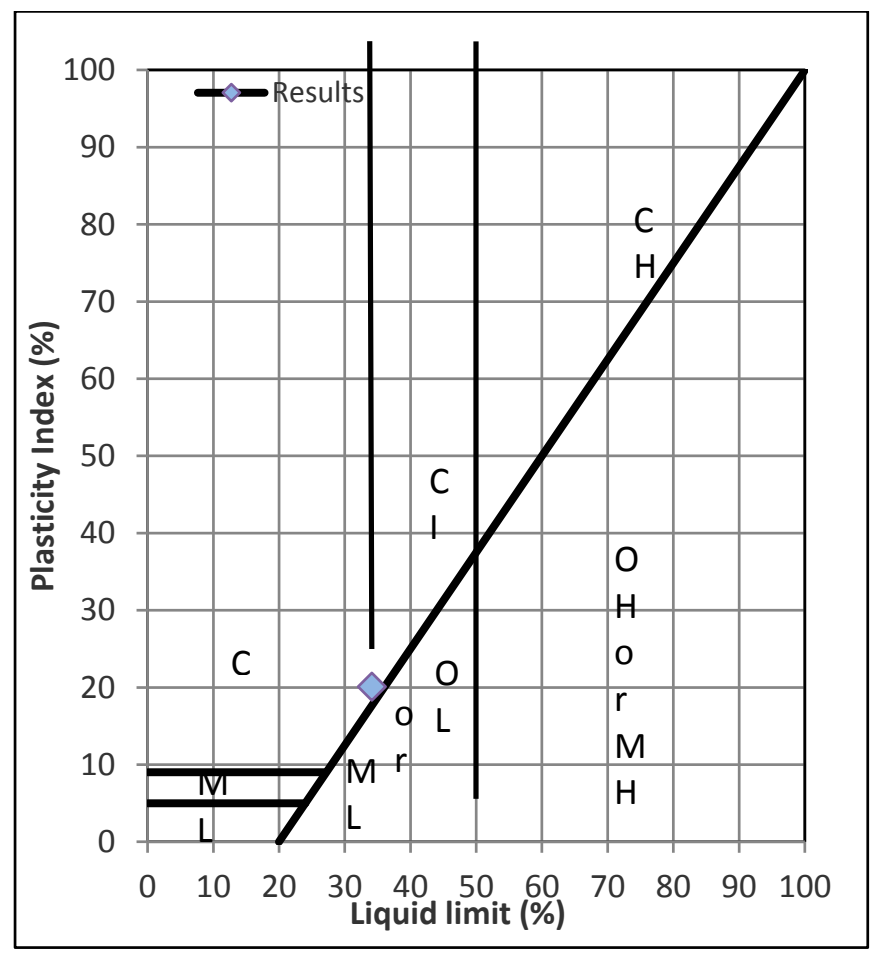

Fig 2: graph of liquid limit and plasticity index

\section{Modified proctor test}

This test is done to fine out the OMC and MDD of soil. These OMC is used for sample preparation for CBR.
Table 2: Modified proctor test on Fly ash

\begin{tabular}{|c|c|c|}
\hline \multicolumn{3}{|c|}{ Modified proctor test on soil alone + \% of fly ashes } \\
\hline Description & OMC \% & MDD $\mathbf{g} \boldsymbol{c c}$ \\
\hline Soil alone & 8.3 & 1.96 \\
\hline Soil + 5\% fly ash & 8.5 & 2.02 \\
\hline Soil + 10\% fly ash & 8.7 & 2.06 \\
\hline Soil + 15\% fly ash & 9.0 & 2.02 \\
\hline
\end{tabular}

As the fly ash percentage increasing, the OMC is also increasing as shown in fig 3 .

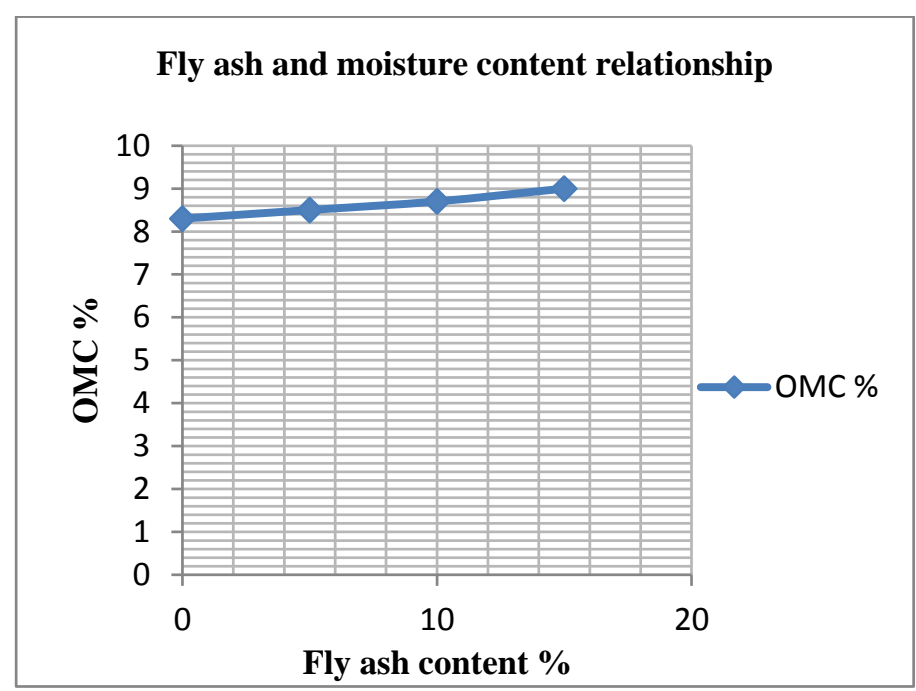

Fig 3: Fly ash content and OMC graph

Fig 4 shows that the MDD is high on $10 \%$ fly ash in the soil and after $10 \%$ fly ash the MDD starts decreasing.

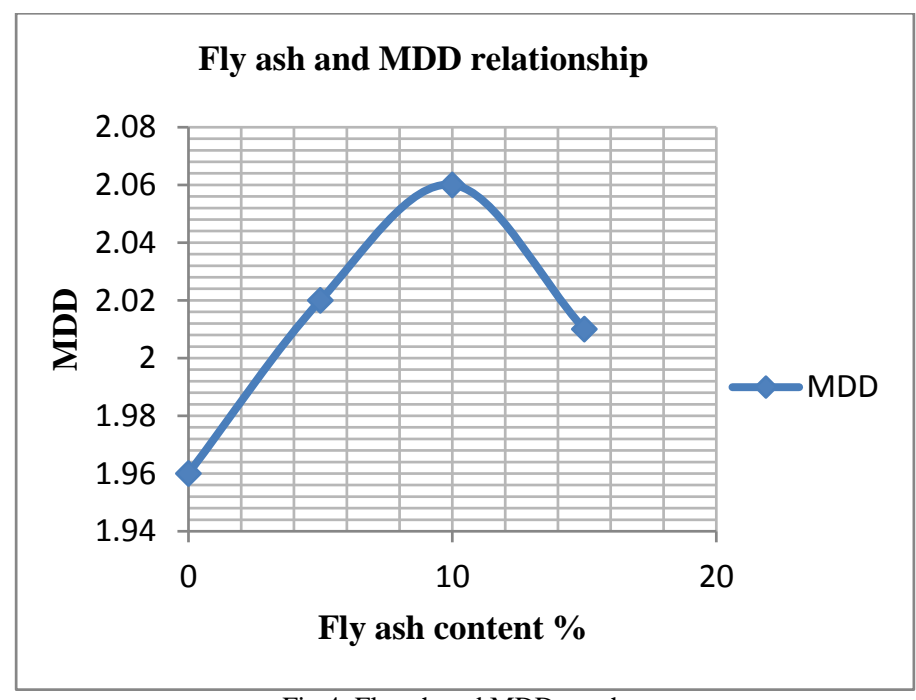

Fig 4: Fly ash and MDD graph 
Table 3: Modified proctor test on RHA

\begin{tabular}{|c|c|c|}
\hline \multicolumn{3}{|c|}{$\begin{array}{l}\text { Modified proctor test on soil alone }+\% \text { of Rice husk ash } \\
\text { (RHA) }\end{array}$} \\
\hline Description & OMC \% & $M D D g / c c$ \\
\hline Soil alone & 8.3 & 1.96 \\
\hline Soil + 5\% RHA & 8.6 & 1.98 \\
\hline Soil + 10\% RHA & 9.2 & 2.01 \\
\hline Soil $+15 \%$ RHA & 9.7 & 1.99 \\
\hline
\end{tabular}

Same as the fly ash, when RHA content increasing the OMC also increasing shown in fig 5. The peak MDD is obtained at $10 \%$ RHA content with soil shown in fig 6.

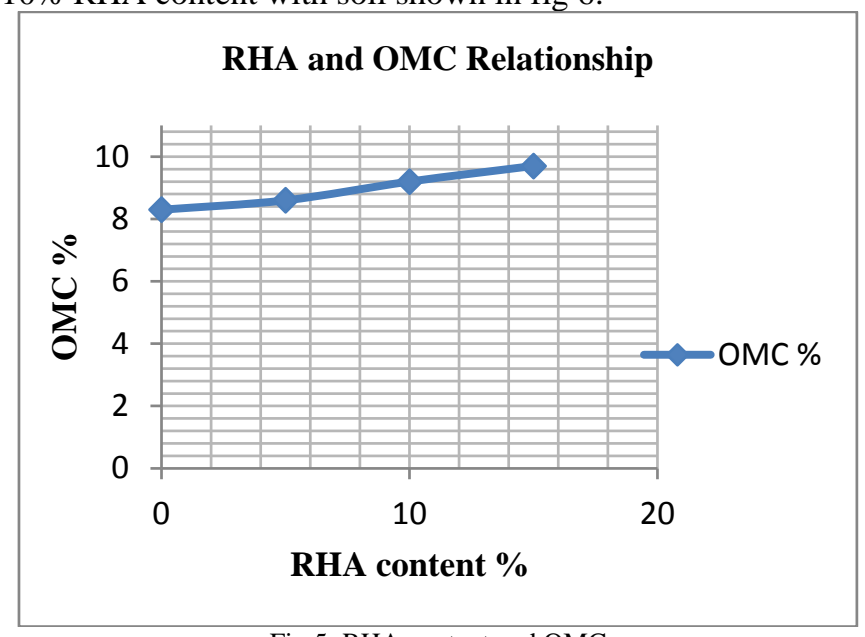

Fig 5: RHA content and OMC

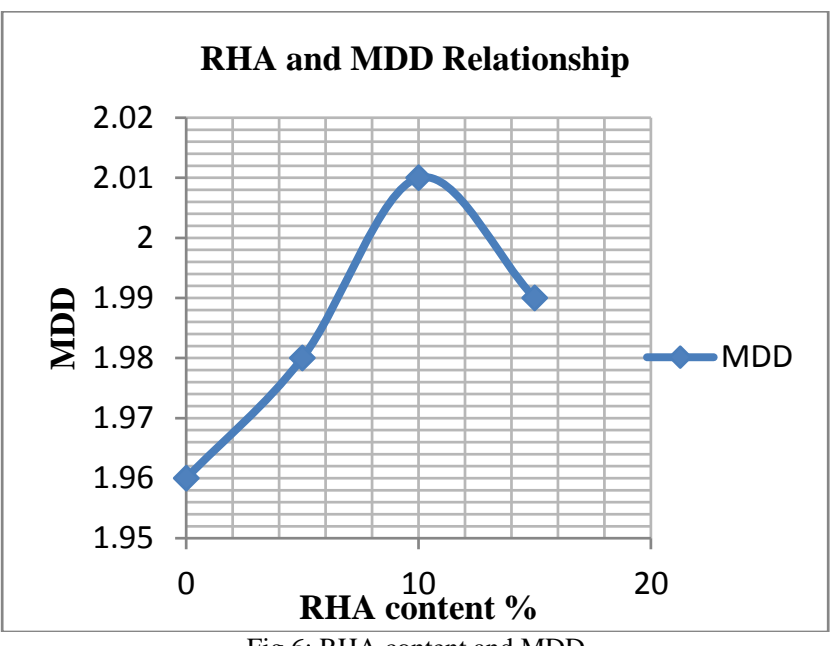

Fig 6: RHA content and MDD

\section{California bearing ratio (soaked)}

A $4.3 \%$ CBR was achieved for natural soil. Further, various percentages of fly ash $(5 \%, 10 \% \& 15 \%)$ were added to soil and samples were prepared, the results are shown in table 4 . Fig 7 shows that the maximum CBR are achieved at $10 \%$ fly ash in soil.

\begin{tabular}{|c|c|}
\hline \multicolumn{2}{|c|}{ Table 4: CBR test on fly ash } \\
\hline Description & $\begin{array}{c}\text { Soaked } \\
\text { CBR \% }\end{array}$ \\
\hline Soil alone & 4.3 \\
\hline Soil + 5\% fly ash & 7.9 \\
\hline Soil + 10\% fly ash & 11 \\
\hline Soil + 15\% fly ash & 9.2 \\
\hline
\end{tabular}

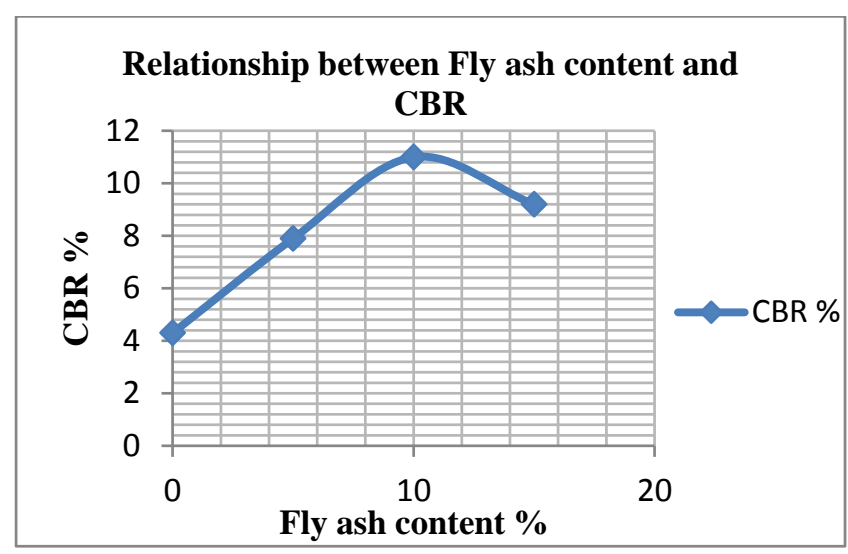

Fig 7: CBR of soil alone and fly ash with soil

Table 5 shows that the percentages of RHA $(5 \%, 10 \%$ \& $15 \%$ ) mix with the soil and the CBR is obtained for these percentages. The peaked soaked CBR for RHA was obtained at $10 \%$ RHA content in soil shown in fig 8.

\begin{tabular}{|c|c|}
\hline \multicolumn{2}{|c}{ Table 5: CBR test on RHA } \\
\hline Description & $\begin{array}{c}\text { Soaked } \\
\text { CBR \% }\end{array}$ \\
\hline Soil alone & 4.3 \\
\hline Soil + 5\% RHA & 6.1 \\
\hline Soil + 10\% RHA & 9.5 \\
\hline Soil + 15\% RHA & 8.9 \\
\hline
\end{tabular}

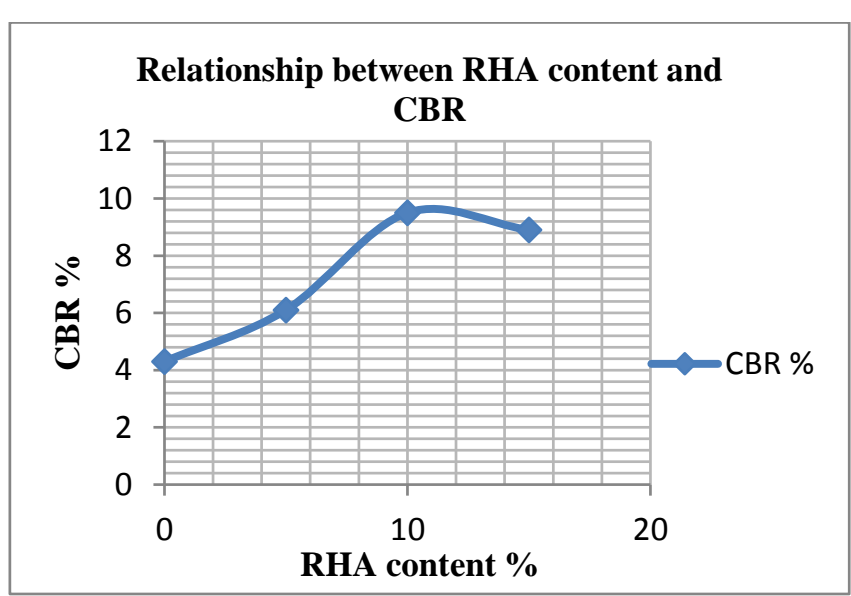

Fig 8: CBR of soil alone and RHA with soil 


\section{E. Road design}

Table 6 and fig 9 shows the thickness of the various layers of road, which is designed for natural soil as a subgrade. The road was designed by nomograph method.

Table 6: Road design on natural soil as subgrade

\begin{tabular}{|c|c|}
\hline Layers & $\begin{array}{c}\text { Thickness } \\
\text { inches }\end{array}$ \\
\hline HMA & 7.5 \\
\hline Base coarse & 6.0 \\
\hline Sub base & 8.0 \\
\hline
\end{tabular}

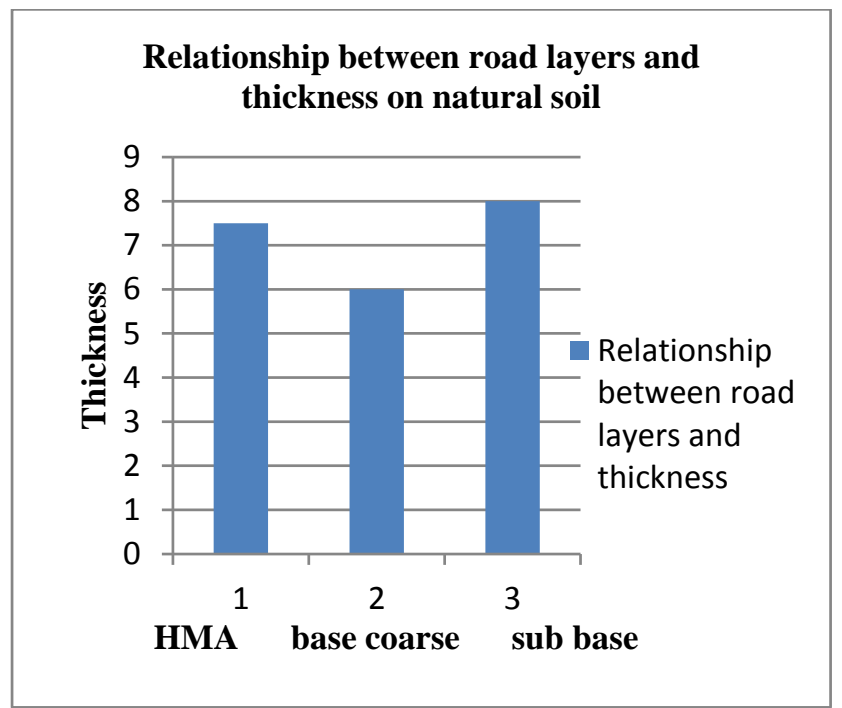

Fig 9: Road design on natural soil as subgrade

Table 7: Road design on 10\% Fly ash in soil
\begin{tabular}{|c|c|}
\hline Layers & $\begin{array}{c}\text { Thickness } \\
\text { inches }\end{array}$ \\
\hline HMA & 7 \\
\hline Base coarse & 6 \\
\hline Sub base & 5 \\
\hline
\end{tabular}

Fig 10 shows the thickness of road layers designed on fly ash with natural soil. As from results, the CBR improved with fly ash so the thickness of the road layer in this case is less compared to design of road on natural soil.

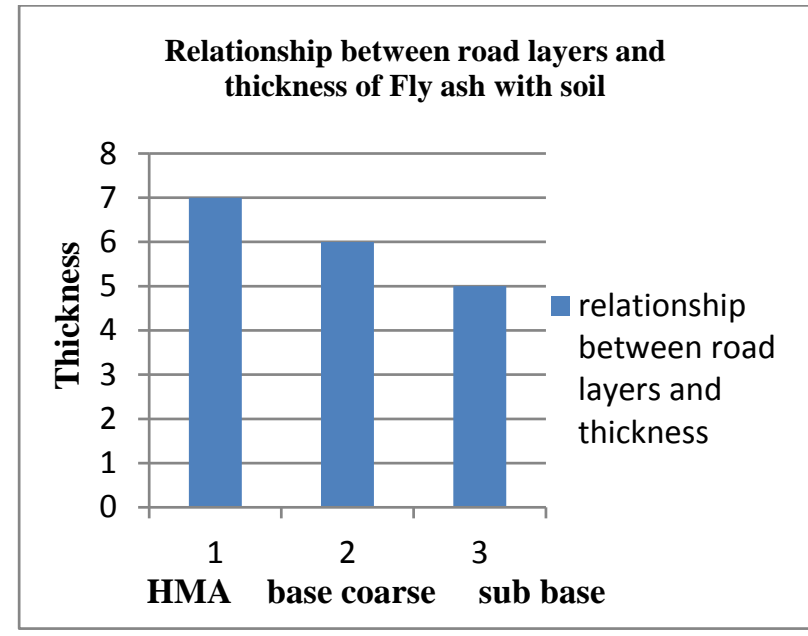

Fig 10: Road designs on $10 \%$ fly ash in soil as a subgrade

Table 8: Road design on $10 \%$ RHA in soil

\begin{tabular}{|c|c|}
\hline Layers & $\begin{array}{c}\text { Thickness } \\
\text { inches }\end{array}$ \\
\hline HMA & 7 \\
\hline Base coarse & 6 \\
\hline Sub base & 5 \\
\hline
\end{tabular}

RHA also resulted in less thickness as compared to thickness of road design on natural soil.

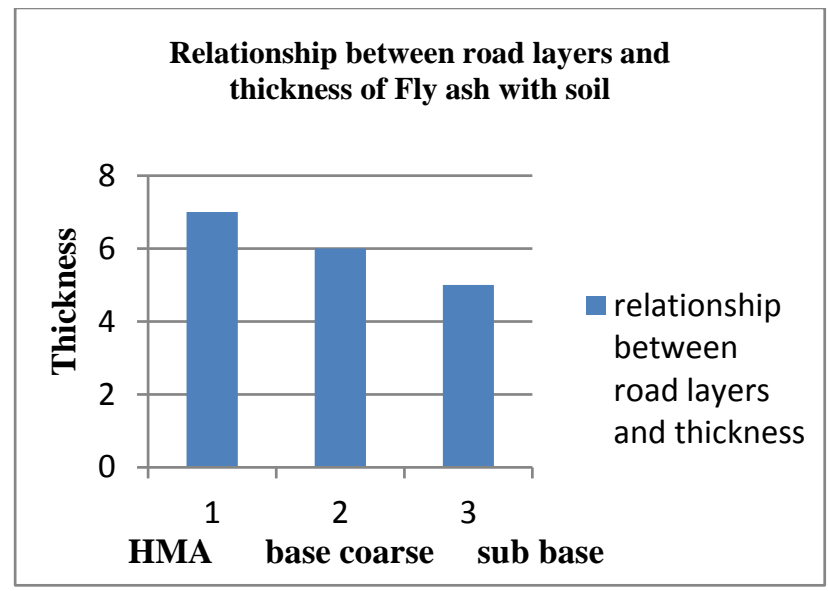

Fig 11: Road design on 10\% RHA in soil as a subgrade

\section{F. Cost estimation}

\begin{tabular}{|c|c|}
\hline \multicolumn{2}{|c}{ Table 9: Cost estimation } \\
\hline Description & $\begin{array}{c}\text { Cost in } \\
\text { millions }\end{array}$ \\
\hline Natural soil & 41.82 \\
\hline Soil + 10\% Fly ash & 39.10 \\
\hline Soil + 10\% RHA & 39.16 \\
\hline
\end{tabular}

Fig 12 shows the detail cost estimation of $1 \mathrm{~km}$ long and $7.62 \mathrm{~m}$ wide road construction on natural soil, fly ash with the soil and RHA with soil. The graph shows fly ash and RHA 
reduced the cost of construction as compared to cost on natural soil.

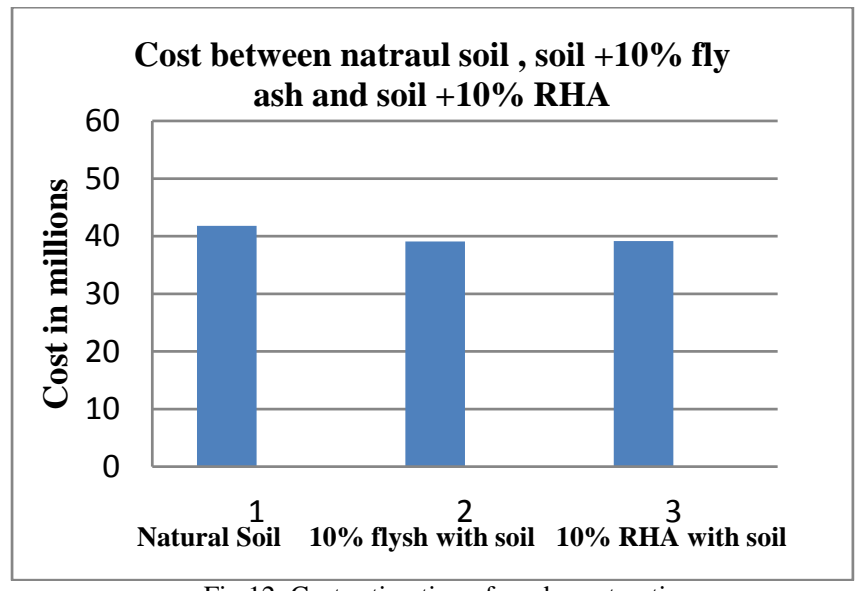

Fig 12: Cost estimation of road construction

\section{CONFLICT OF INTEREST}

The content of this paper is original, not copied from anywhere and free of plagiarism. The previous work is referenced below.

\section{CONCLUSION}

- Soil with different percentages of fly ash gives a peak value of CBR at $10 \%$ fly ash. It increases from $4.3 \%$ to $11 \%$. After $10 \%$ addition of fly ash, the strength of subgrade starts decreasing.

- Same as the fly ash, RHA also improves the soil CBR at $10 \%$ RHA content in soil. CBR increases from $4.3 \%$ to $8.9 \%$. After $10 \%$, adding of RHA the CBR of subgrade starts decreasing.

- From the results it is evident that fly ash improves the soil CBR significantly as compared to RHA.

- In road designing, fly ash and RHA resulted in less thickness of road layers as compared to road design on natural soil.

- The detailed cost estimation of road construction shows the fly ash and RHA cost is comparatively less than the natural soil.

\section{ACKNOWLEDGEMENT}

The author is thankful to the Pakhtunkhwa Highways Authority (PKHA) department in order to perform tests in their laboratory. Author is also thankful to his supervisors for their continuous support throughout the study.

\section{REFERENCES}

[1] Acosta, H. A., T. B. Edil, and C. H. Benson. "Soil stabilization and drying using fly ash." Geo Engineering Rep 3 (2003).

[2] Alhassan, Musa. "Potentials of rice husk ash for soil stabilization." Assumption university journal of technology 11.4: 246-250 2008.
[3] Bhuvaneshwari, S., R. G. Robinson, and S. R. Gandhi. "Stabilization of expansive soils using fly ash." Fly Ash India 8: 1-10 2005.

[4] Brooks, Robert M. "Soil stabilization with fly ash and rice husk ash." International Journal of Research and Reviews in Applied Sciences 1.3 209-217 2009

[5] Fattah, Mohammed Y., Falah H. Rahil, and Kawther YH Al-Soudany. "Improvement of clayey soil characteristics using rice husk ash." Journal of Civil Engineering and Urbanism 3.1: 12-18 2013.

[6] Ji-ru, Zhang, and Cao Xing. "Stabilization of expansive soil by lime and fly ash." Journal of Wuhan University of Technology-Mater. Sci. Ed. 17.4: 73-77 2002

[7] Keshawarz, M. Saleh, and Utpal Dutta. "Stabilization of south Texas soils with fly ash." Fly ash for soil improvement. ASCE Geotechnical special publication No.36 1993

[8] Mackiewicz, Scott M., and E. Glen Ferguson. "Stabilization of soil with self-cementing coal ashes." World of Coal Ash (WOCA): 1-7 2005.

[9] Prakash, J., K. Kumari, and V. Kunar. "Stabilization of Soil using Rice Husk Ash." International Journal of Innovative Research in Science, Engineering and Technology 6.7: 12997-13003 2017.

[10] Ramaji, Amin Esmaeil. "A review on the soil stabilization using low-cos methods." Journal of Applied Sciences Research 8.4: 2193-2196 2012.

[11] Rathan Raj, R., S. Banupriya, and R. Dharani. "Stabilization of soil using rice husk ash." International Journal of Computational Engineering Research (IJCER), ISSN (e): 2250-3005 2016

[12] Tastan, Erdem O., et al. "Stabilization of organic soils with fly ash." Journal of geotechnical and Geo environmental Engineering 137.9: 8198332011

[13] Yadu, Laxmikant, Rajesh Kumar Tripathi, and Dharamveer Singh "Comparison of fly ash and rice husk ash stabilized black cotton soil." International Journal of Earth Sciences and Engineering 4.06 (2011): 42 45 .

[14] https://www.fhwa.dot.gov/pavement/recycling/fach01.cfm

[15] Zha, Fusheng, et al. "Behavior of expansive soils stabilized with fly ash." Natural hazards 47.3 (2008): 509-523.

[16] Zia, Nayyar, and Patrick J. Fox. "Engineering properties of loess-fly ash mixtures for roadbase construction." Transportation Research Record 1714.1 (2000): $49-56$

[17] Zumrawi, Magdi ME. "Stabilization of pavement subgrade by using fly ash activated by cement." American journal of civil engineering and architecture 3.6 (2015): 218-224

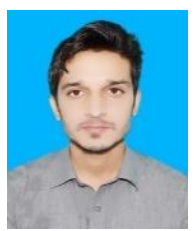

Afaq Ali, the author, belongs to Pabbi, Nowshera, Pakistan. He did a Bachelor of Civil Engineering from Sarhad University of Science \& Information Technology Peshawar in 2016. The author is continuing his master's degree in Transportation Engineering from Sarhad University of Science \& Information Technology, Peshawar. This study is his research work for the master's degree. 